\title{
Low-dose Gamma Knife surgery for nonfunctioning pituitary adenomas
}

\author{
Clinical article
}

\author{
Amr M. N. El-Shehaby, M.D., Ph.D., Wael A. Reda, M.D., Ph.D., \\ Sameh R. Tawadros, M.B.B.Ch., and Khaled M. Abdel Karim, M.D., Ph.D. \\ Gamma Knife Center Cairo, Nasser Institute, Shobra; and Ain Shams University, Faculty of Medicine, \\ Abbassiya, Cairo, Egypt
}

Object. The primary concern when performing Gamma Knife surgery for pituitary adenoma is preservation of vision and pituitary function while achieving tumor growth control. Higher prescribed radiation doses are typically correlated with higher incidences of postradiosurgical hormone deficiencies. The goal of the present study was to retrospectively analyze the feasibility of using a lower prescribed radiation dose in the treatment of nonfunctioning pituitary adenomas and the effect of this dose on vision, pituitary function, and tumor growth control.

Methods. The study was conducted in 38 patients with nonfunctioning pituitary adenomas, who were treated between January 2002 and July 2008. Twenty-one patients were available for follow-up (13 men and 8 women). The mean follow-up period was 44 months (range 24-90 months). Nineteen patients had previously undergone surgery. Pituitary dysfunction developed after surgery in 3 patients. One patient had an abnormal pituitary hormone profile before radiosurgery due to an attack of pituitary apoplexy. Visual field defects were present in 12 patients. The prescribed radiation dose was $12 \mathrm{~Gy}$ in all patients. The tumor volume ranged from 0.5 to $11.8 \mathrm{~cm}^{3}\left(\mathrm{mean} 4.8 \mathrm{~cm}^{3}\right)$. The maximum dose to the visual pathway was kept below $10 \mathrm{~Gy}$. The mean maximum dose delivered to the visual pathway was 7.9 Gy.

Results. The patients were followed up for a period of 24 to 90 months (mean 44 months). The size of the tumor decreased in 11 patients (52\%) and remained stable in 9 patients (43\%). In 1 patient there was tumor growth outside the previous radiation field (on the contralateral side). Among the 12 patients with visual field defects, 9 (75\%) experienced an improvement and the remaining patients' vision remained stable. In only 4 patients was the visual improvement associated with tumor shrinkage. The hormone profile remained normal in all patients except for the 4 patients who had pituitary dysfunction before radiosurgery.

Conclusions. The 12-Gy prescribed dose used in this study seems to be sufficient for producing tumor control while sparing the patient from radiation-induced pituitary dysfunction. In addition, visual improvement was reported in a number of cases. A larger series and longer follow-up are required to confirm these results.

(http://thejns.org/doi/abs/10.3171/2012.6.GKS12986)

\section{KEY WORDS • stereotactic radiosurgery - low-dose radiosurgery • nonfunctioning pituitary adenoma}

$\mathrm{T}$ HE efficacy and necessity of SRS for the treatment of residual and recurrent nonfunctioning pituitary adenomas, and even as a primary therapy in some instances, have been demonstrated in several stud-

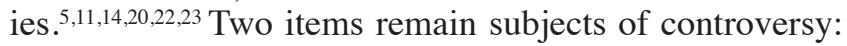
the first is the minimum effective dose and the second is occurrence of postradiosurgical pituitary insufficiency. Both items are related, as some studies have shown a relationship between the prescribed dose and hormonal insufficiency. ${ }^{4,8}$ Another item of interest is the effect of a lower dose on tumor control.

\footnotetext{
Abbreviations used in this paper: GKS = Gamma Knife surgery; $\mathrm{SRS}=$ stereotactic radiosurgery
}

\section{Methods}

\section{Patient Population}

This study initially involved 38 patients with nonfunctioning pituitary adenomas, who were treated between January 2002 and July 2008. Twenty-one patients were available for follow-up (13 men and 8 women), and these patients comprised the study group. The patients' ages ranged from 31 to 70 years (mean 48 years). The mean follow-up period was 44 months (range 24-90 months). Nineteen patients previously had undergone surgery (between 1 and 4 operations each).

Visual field defects were present in 12 patients. Duration of the field defect ranged from 5 to 84 months. Six 
patients presented with headache and 2 patients presented with ocular nerve palsy. Pituitary dysfunction developed after surgery in 3 patients. One patient had an abnormal pituitary hormone profile before radiosurgery due to an attack of pituitary apoplexy.

Twelve patients had tumors in direct contact with, or within $2 \mathrm{~mm}$ from, the visual pathway at the time of treatment. Nine of these patients had associated visual field defects.

\section{Radiosurgical Parameters}

After a local anesthetic agent had been applied to the head, the patients received placement of the Leksell stereotactic head frame (model G, Elekta AB). High-resolution gadolinium-enhanced MRI was performed using a 1.5-T Genesis Sigma MR unit (General Electric). Magnetic resonance imaging was the only imaging technique used. The MRI sequences were T1 weighted with addition of contrast agent and 1.6-mm slice thickness. Images were transported to the GammaPlan 5.32 workstation (Elekta AB). Treatment planning included drawing of the target and delineation of the anterior visual pathway. Radiation coverage was generally intended to be $90 \%$ or more of the target; however, in some cases in which the tumor was in direct contact with the optic apparatus, coverage was intended to be at least $80 \%-85 \%$ of the tumor receiving the prescribed dose.

We maintained a small less-irradiated area close to the optic apparatus. The maximum dose directed at the optic apparatus was maintained below 9 Gy when possible, without significant compromise of the tumor cover. Otherwise, in situations in which the maximum dose exceeded 9 Gy, a dose-volume histogram was created and the volume of anterior visual pathway receiving more than 9 Gy was kept lower than $10 \mathrm{~mm}^{3}$ (Table 1).

\section{Follow-Up}

Follow-up examinations were planned at 6-month intervals for the first 2 years and annually thereafter. Every patient's history and examination findings were recorded and compared with those documented prior to treatment. Radiological follow-up was undertaken by performing contrast-enhanced MRI. A formal computerized visual field examination was performed at every follow-up examination, and a complete hormone profile was recorded beginning at the end of the 2 years' follow-up.

Tumor volume changes were assessed in 2 ways on MR images. We made the first assessment by taking measurements using a micrometer screw gauge in the axial, coronal, and sagittal planes. Tumor shrinkage was only confirmed to be present if it could be demonstrated in 2 planes. In addition to this method, we made a qualitative assessment by registering any change in tumor contour or noting retraction of the tumor away from normal tissue (for example, the optic chiasm).

The perimetry findings were compared both in respect to overall appearance and the quantitative data registered on the forms.

Hormone assessments included measurements of adrenocorticotropic hormone and basal serum cortisol, free thyroxine, thyroid-stimulating hormone, luteinizing hor-

\section{TABLE 1: Radiosurgical treatment parameters}

\begin{tabular}{lc}
\hline \multicolumn{1}{c}{ Radiosurgical Parameter } & Value \\
\hline mean tumor vol (range) & $4.8 \pm 2.9 \mathrm{~cm}^{3}\left(0.5-11.8 \mathrm{~cm}^{3}\right)$ \\
prescribed dose in all patients & $12 \mathrm{~Gy}$ \\
mean percentage of coverage (range) & $91 \pm 6 \%(70-98 \%)$ \\
mean integral dose (range) & $76.4 \pm 42.9 \mathrm{~mJ}(8.5-178.2 \mathrm{~mJ})$ \\
$\begin{array}{l}\text { mean max dose to anterior visual } \\
\text { pathway (range) }\end{array}$ & $7.9 \pm 2.4 \mathrm{~Gy}(3.2-12.5 \mathrm{~Gy})$ \\
\hline
\end{tabular}

mone, follicle-stimulating hormone, prolactin, and growth hormone serum levels.

\section{Statistical Analysis}

We used IBM SPSS statistics (version 19.0, IBM Corp.) for the data analysis. In this paper, data are expressed as means \pm SDs for quantitative parametric measures and as both number and percentage for categorized data.

The following tests were performed: 1) a comparison between 2 independent groups for nonparametric data using the Wilcoxon rank-sum test; and 2) a Chi-square test to study the association between 2 variables or a comparison between 2 independent groups as regards the categorized data. The probability of error at 0.05 was considered significant, whereas probabilities of error at 0.01 and 0.001 were considered highly significant.

\section{Results}

The patients were followed up for a period of 24 to 90 months (mean 44 months). The tumor decreased in size in 11 patients (52\%) and remained stable in 9 patients (43\%). In 1 patient there was tumor growth outside the previous radiation field on the contralateral side.

Among the 12 patients with visual field defects, 9 (75\%) experienced an improvement and the remaining patients' vision remained stable. In the 2 patients with ocular nerve palsy before treatment, 1 patient's palsy remained unchanged and the other's palsy improved. In only 4 patients was the visual improvement associated with tumor shrinkage. In other words, among patients in whom tumor size remained unchanged, $56 \%$ of patients experienced visual improvement, as opposed to $44 \%$ of patients whose visual status was unchanged. Contrary to what we expected, only $33 \%$ of patients with tumor shrinkage had visual improvement; $67 \%$ had an unchanged visual field (Fig. 1).

Regarding the 12 patients who harbored tumors in direct contact with, or within $2 \mathrm{~mm}$ from, the anterior optic apparatus, there was improvement in visual fields in $7 \mathrm{pa}-$ tients (Fig. 2) and stable findings in the rest. In 5 patients the tumor shrank, and in 7 patients the tumor remained stable in size. In 1 patient the tumor progressed but outside the radiation field (on the contralateral side). In this group of patients, $57 \%$ of patients in whom the tumors appeared unchanged experienced visual improvement and $60 \%$ of patients in whom there was tumor shrinkage had visual improvement (Fig. 3). 


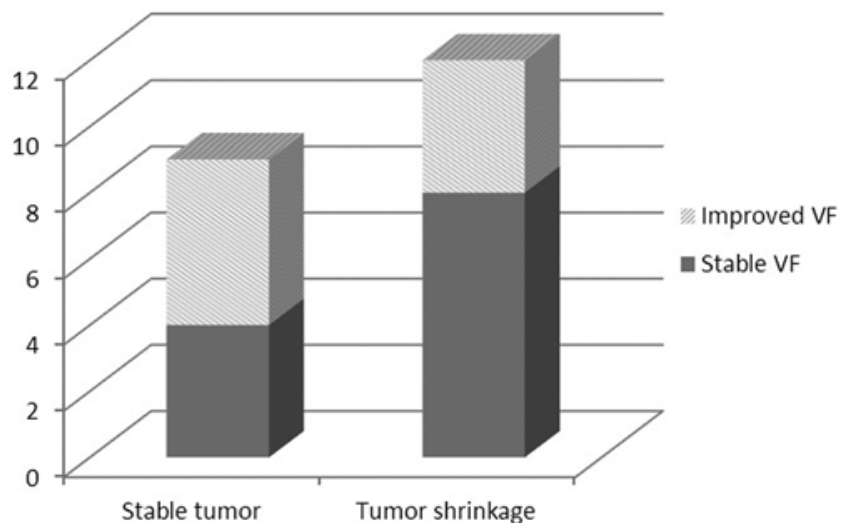

Fig. 1. Three-dimensional bar graph showing the relationship between the size of the tumor after treatment and visual field (VF) outcome in patients in this study. Numbers on the y axis represent numbers of patients.

Pituitary hormone levels remained within normal values in all but 4 patients who had pituitary dysfunction prior to radiosurgery.

\section{Discussion}

For decades the most widely used treatment for nonfunctioning pituitary adenomas has been transsphenoidal surgery. However, in the presence of supra- and parasellar tumor extensions, complete resection may be unattainable (46\%-75\% of all surgical cases) ${ }^{3,6,17}$ The results of surgery alone demonstrate long-term recurrence rates of $50 \%-85 \% .^{21,27,29}$

Traditionally, conventional fractionated radiotherapy was used to treat residual tumors to prevent regrowth and prevent new neurological symptoms. However, despite acceptable tumor growth control rates, the major problem with this form of radiation treatment was the considerably high rate and severity of its complications. These included a $1 \%-7 \%$ risk of delayed optic neuropathy and a $50 \%-100 \%$ rate of long-term pituitary hormonal deficiency. $1,2,10,12,13,15,19,26$ This led to the emergence of SRS as a safer and equally effective form of radiation treatment. The tumor control rates associated with SRS for nonfunctional pituitary tumors range from $87 \%$ to $97 \%$ and the regression rates from $42 \%$ to $78 \%{ }^{5,11,14,20,22,23}$ In the present study, the tumor control rate was $95 \%$ and the regression rate was $52 \%$, values consistent with those of previously cited studies.

The 2 main topics of concern and controversy regarding radiosurgical treatment of pituitary adenomas are the optimal dose and effect of radiosurgery on hormone function in the normal hypophysis. The radiosurgical doses selected for nonfunctioning pituitary adenomas are usually lower than those deemed necessary for functioning adenomas. However, the optimal dose for a nonfunctioning pituitary tumor remains unclear. Losa et al. ${ }^{11}$ demonstrated that the radiation dose applied to the periphery of the tumor was significantly higher in patients in whom the tumor reduced in size, compared with patients in whom there was no change in tumor volume. In that study, however, the mean prescribed doses were 17

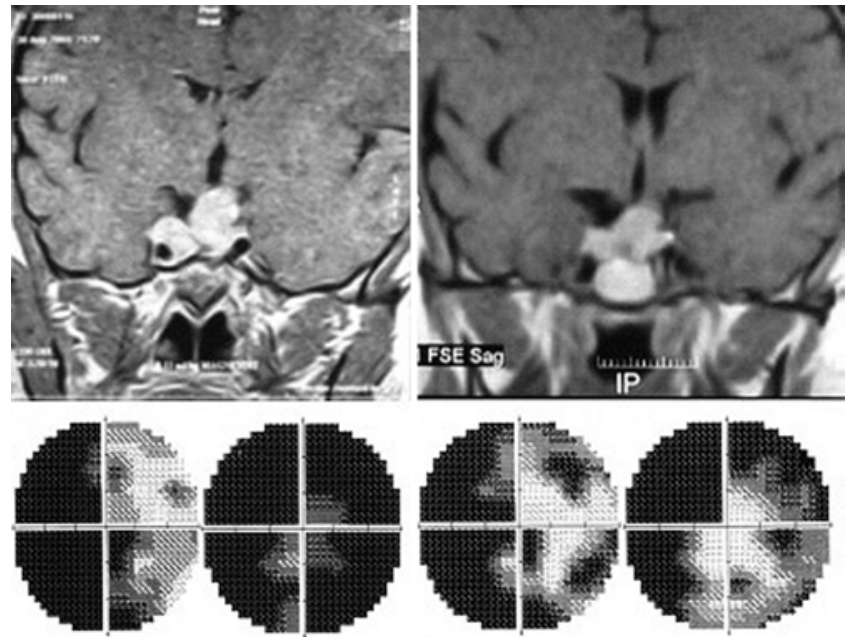

FIG. 2. Magnetic resonance images and computerized images of the visual field obtained before GKS (left) and 75 months after GKS (right). This patient initially presented with bilateral optic atrophy. She underwent transsphenoidal surgery, which resulted in improvement in the left visual field alone, while her right eye was almost blind. During GKS, a $7.2-\mathrm{cm}^{3}$ tumor was treated with 12 Gy to the $45 \%$ isodose with $70 \%$ coverage. The excess dose went into the skull base. The maximum dose to the visual pathways was $8.5 \mathrm{~Gy}$, and only $9 \mathrm{~mm}^{3}$ received more than $8 \mathrm{~Gy}$. At the latest follow-up, 75 months after GKS, there was evidence of tumor regression and bilateral visual field improvement, especially in the right temporal field (right).

Gy for the former group and 15 Gy for the latter, which are higher than the doses used in the present study. Despite this, we demonstrated a $52 \%$ rate of tumor reduction. Sheehan et al. ${ }^{23}$ noted that a margin dose of 13-14 Gy was effective. Mingione et al. ${ }^{14}$ reported that the lowest margin dose capable of producing tumor shrinkage was 12 Gy. Park et al. ${ }^{20}$ used univariate analysis to demonstrate that a low radiation dose directed at the tumor margin ( $\leq$ $13 \mathrm{~Gy}$ ) was a significant risk factor for tumor recurrence $(\mathrm{p}=0.034)$. However, this factor did not remain significant in multivariate testing $(\mathrm{p}=0.892)$.

Tumor growth control could be achieved in tumors that adhered or were close to the optic apparatus in all 11

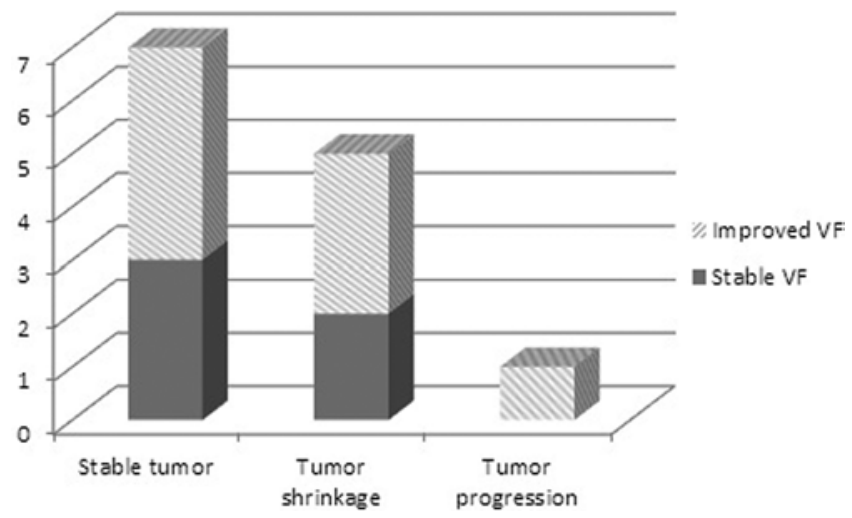

FIG. 3. Three-dimensional bar graph showing the relationship between posttreatment tumor size and visual field outcome in tumors that were either in direct contact with, or within $2 \mathrm{~mm}$ from, the optic apparatus. In the single case of tumor progression, the recurrent lesion was identified on the side contralateral to the previously treated tumor. 
patients in the present series. This finding was also demonstrated by Mingione et al. ${ }^{14}$ and Iwai et al. ${ }^{5}$ Neither of their studies found a difference in tumor growth control based on the distance between the lesion and the optic apparatus. The authors noted that if most of the lesion received a sufficient dose, tumor growth control could be achieved. This is contrary to results reported by Park et al. ${ }^{20}$ who found a difference in growth control based on the lesion's proximity to the optic apparatus, but this difference did not reach statistical significance. There were no cases of radiation-related cranial nerve neuropathy.

The anterior optic apparatus is known as the most radiosensitive intracranial structure. Stafford et al. ${ }^{24}$ reported that a dose of 12 Gy or less is associated with a $1.1 \%$ risk of optic neuropathy. Recently, it was found that a dose of 10 Gy or less directed at a small volume of the optic apparatus can be considered relatively safe., ${ }^{78}$ That is why in our study we persistently tried to keep the dose to the anterior visual pathway below 9 Gy and, as a consequence, there were no cases of optic neuropathy. The cranial nerves that pass through the cavernous sinus can tolerate doses of up to $40 \mathrm{~Gy} ;{ }^{25}$ thus there was no risk of injury from the low dose that was used.

Some studies have demonstrated that the radiation dose directed to tumors that fail to respond is not significantly different from that directed to other tumors that do respond. ${ }^{23}$ Park et al. ${ }^{20}$ found that tumor control occurred less often in patients who earlier had experienced 2 or more recurrences, with univariate and multivariate analyses showing significance at $\mathrm{p}<0.001$ and $\mathrm{p}=0.01$, respectively. Tumor aggressiveness should be considered. Recurrence on the contralateral side, which occurred in this study, was reported in 2 other studies. ${ }^{11,22}$ This may be related to tumor cells left in the lateral walls of the sella turcica following transsphenoidal surgery, which are not immediately detected on imaging studies and become visable after they have proliferated to a larger size. Also noteworthy is the fact that visual improvement was not exclusively associated with tumor shrinkage, as would be expected. On the contrary, a greater number of patients in whom tumor size remained unchanged displayed visual improvement.

It has been reported frequently that SRS for nonfunctioning pituitary adenomas is associated with a risk of developing hypopituitarism in $0 \%-28 \%$ of cases. ${ }^{5,11,14,16,22,23}$ In these reports, however, no reference is made to the prescribed dose given in patients in whom a hormonal deficit developed or to whether any of these patients received prior radiotherapy. Other authors have not indicated whether there was an initial hormone imbalance in their patients ${ }^{16}$ and those authors who did grouped patients with normal pituitary function with those with partial pituitary dysfunction. ${ }^{14}$ In a study by Pollock et al. ${ }^{22}$ the risk of developing a hormonal deficit was related to tumor size (for tumors $\leq 4 \mathrm{~cm}^{3}$ the risk was $18 \%$, whereas for tumors $>4 \mathrm{~cm}^{3}$ the risk was 50\%) and length of follow-up with an incidence of $32 \%$ at 5 years. Prior radiotherapy, advanced patient age, and length of follow-up have been determined to be factors contributing to the development of new hormonal deficits after SRS.

Some studies have correlated the occurrence of new hormonal deficits with the dose given to the pituitary gland and pituitary stalk. ${ }^{4,8}$ Feigl et al. ${ }^{4}$ reported that patients who received a higher mean point dose to the pituitary stalk $(6.5 \pm 3.8$ Gy vs $4.1 \pm 2.8 \mathrm{~Gy})$ and the pituitary gland $(12.4 \pm 6.5$ Gy vs $9.5 \pm 7.1 \mathrm{~Gy})$ were more likely to develop new hormonal deficits after GKS. It has been suggested that it is the mean dose and not the maximum dose to the pituitary gland that is the most important factor in the development of hypopituitarism.9,28 Vladyka et al. ${ }^{28}$ hypothesized that the mean dose represented the dose delivered to the whole volume of the hypophysis, whereas the maximum dose was received only by a small amount of tissue. That is why it may be less significant in influencing the function of the whole hypophysis. Liscák et al. ${ }^{9}$ reported a differential radiosensitivity within normal pituitary tissue, because they observed that the mean limiting dose for gonadotropic and thyrotropic function was $15 \mathrm{~Gy}$, whereas the mean limiting dose to the hypophysis for adrenocorticotropic function was 18 Gy. Those authors also determined that previous surgery was a contributing factor to the development of hypopituitarism. There were 3 patients with pituitary dysfunction in our study, and in all cases this dysfunction occurred after surgery.

In this study there were no patients in whom new hormonal deficits developed. We postulate that this may be due to the uniformly lower prescription dose (12 Gy) that we used to treat these tumors. To the best of our knowledge, this is the only study of radiosurgical treatment of nonfunctioning pituitary adenomas in which the same low prescription dose was used in a consecutive group of patients. Whether this dose will succeed in producing longer-term tumor control, and whether normal pituitary function will be maintained, will require a longer follow-up.

\section{Conclusions}

The 12-Gy prescribed dose used in this study seems to be sufficient for producing tumor control while sparing the patient from radiation-induced pituitary dysfunction. In addition, visual improvement occurred in a number of cases. A larger series and longer follow-up are required to confirm these results.

\section{Disclosure}

The authors report no conflict of interest concerning the materials or methods used in this study or the findings specified in this paper.

Author contributions to the study and manuscript preparation include the following. Conception and design: Reda, Karim. Acquisition of data: Tawadros, Karim. Analysis and interpretation of data: El-Shehaby. Drafting the article: El-Shehaby. Critically revising the article: Reda. Reviewed submitted version of manuscript: Reda. Approved the final version of the manuscript on behalf of all authors: Reda. Statistical analysis: El-Shehaby. Study supervision: Reda, El-Shehaby.

\section{References}

1. Brada M, Rajan B, Traish D, Ashley S, Holmes-Sellors PJ, Nussey S, et al: The long-term efficacy of conservative surgery and radiotherapy in the control of pituitary adenomas. Clin Endocrinol (Oxf) 38:571-578, 1993 
2. Breen P, Flickinger JC, Kondziolka D, Martinez AJ: Radiotherapy for nonfunctional pituitary adenoma: analysis of longterm tumor control. J Neurosurg 89:933-938, 1998

3. Chang EF, Zada G, Kim S, Lamborn KR, Quinones-Hinojosa A, Tyrrell JB, et al: Long-term recurrence and mortality after surgery and adjuvant radiotherapy for nonfunctional pituitary adenomas. J Neurosurg 108:736-745, 2008

4. Feigl GC, Pistracher K, Berghold A, Mokry M: Pituitary insufficiency as a side effect after radiosurgery for pituitary adenomas: the role of the hypothalamus. Clinical article. J Neurosurg 113 Suppl:153-159, 2010

5. Iwai Y, Yamanaka K, Yoshioka K: Radiosurgery for nonfunctioning pituitary adenomas. Neurosurgery 56:699-705, 2005

6. Kurosaki M, Lüdecke DK, Flitsch J, Saeger W: Surgical treatment of clinically nonsecreting pituitary adenomas in elderly patients. Neurosurgery 47:843-849, 2000

7. Leber KA, Berglöff J, Pendl G: Dose-response tolerance of the visual pathways and cranial nerves of the cavernous sinus to stereotactic radiosurgery. J Neurosurg 88:43-50, 1998

8. Leenstra JL, Tanaka S, Kline RW, Brown PD, Link MJ, Nippoldt TB, et al: Factors associated with endocrine deficits after stereotactic radiosurgery of pituitary adenomas. Neurosurgery 67:27-33, 2010

9. Liscák R, Vladyka V, Marek J, Simonová G, Vymazal J: Gamma knife radiosurgery for endocrine-inactive pituitary adenomas. Acta Neurochir (Wien) 149:999-1006, 2007

10. Littley MD, Shalet SM, Beardwell CG, Ahmed SR, Applegate G, Sutton ML: Hypopituitarism following external radiotherapy for pituitary tumours in adults. Q J Med 70:145-160, 1989

11. Losa M, Valle M, Mortini P, Franzin A, da Passano CF, Cenzato $\mathrm{M}$, et al: Gamma knife surgery for treatment of residual nonfunctioning pituitary adenomas after surgical debulking. J Neurosurg 100:438-444, 2004

12. McCord MW, Buatti JM, Fennell EM, Mendenhall WM, Marcus RB Jr, Rhoton AL, et al: Radiotherapy for pituitary adenoma: long-term outcome and sequelae. Int J Radiat Oncol Biol Phys 39:437-444, 1997

13. Milker-Zabel S, Debus J, Thilmann C, Schlegel W, Wannenmacher M: Fractionated stereotactically guided radiotherapy and radiosurgery in the treatment of functional and nonfunctional adenomas of the pituitary gland. Int $\mathbf{J}$ Radiat Oncol Biol Phys 50:1279-1286, 2001

14. Mingione V, Yen CP, Vance ML, Steiner M, Sheehan J, Laws $\mathrm{ER}$, et al: Gamma surgery in the treatment of nonsecretory pituitary macroadenoma. J Neurosurg 104:876-883, 2006

15. Minniti G, Traish D, Ashley S, Gonsalves A, Brada M: Fractionated stereotactic conformal radiotherapy for secreting and nonsecreting pituitary adenomas. Clin Endocrinol (Oxf) 64: 542-548, 2006

16. Mokry M, Ramschak-Schwarzer S, Simbrunner J, Ganz JC, Pendl G: A six year experience with the postoperative radiosurgical management of pituitary adenomas. Stereotact Funct Neurosurg 72 (Suppl 1):88-100, 1999

17. Mortini P, Losa M, Barzaghi R, Boari N, Giovanelli M: Results of transsphenoidal surgery in a large series of patients with pituitary adenoma. Neurosurgery 56:1222-1233, 2005

18. Ove R, Kelman S, Amin PP, Chin LS: Preservation of visual fields after peri-sellar gamma-knife radiosurgery. Int J Cancer 90:343-350, 2000
19. Paek SH, Downes MB, Bednarz G, Keane WM, Werner-Wasik $\mathrm{M}$, Curran WJ Jr, et al: Integration of surgery with fractionated stereotactic radiotherapy for treatment of non-functioning pituitary macroadenomas. Int J Radiat Oncol Biol 61:795808,2005

20. Park KJ, Kano H, Parry PV, Niranjan A, Flickinger JC, Lunsford LD, et al: Long-term outcomes after gamma knife stereotactic radiosurgery for nonfunctional pituitary adenomas. Neurosurgery 69:1188-1199, 2011

21. Park P, Chandler WF, Barkan AL, Orrego JJ, Cowan JA, Griffith KA, et al: The role of radiation therapy after surgical resection of nonfunctional pituitary macroadenomas. Neurosurgery 55:100-107, 2004

22. Pollock BE, Cochran J, Natt N, Brown PD, Erickson D, Link MJ, et al: Gamma knife radiosurgery for patients with nonfunctioning pituitary adenomas: results from a 15-year experience. Int J Radiat Oncol Biol Phys 70:1325-1329, 2008

23. Sheehan JP, Kondziolka D, Flickinger J, Lunsford LD: Radiosurgery for residual or recurrent nonfunctioning pituitary adenoma. J Neurosurg 97 (5 Suppl):408-414, 2002

24. Stafford SL, Pollock BE, Leavitt JA, Foote RL, Brown PD, Link MJ, et al: A study on the radiation tolerance of the optic nerves and chiasm after stereotactic radiosurgery. Int J Radiat Oncol Biol Phys 55:1177-1181, 2003

25. Tishler RB, Loeffler JS, Lunsford LD, Duma C, Alexander E III, Kooy HM, et al: Tolerance of cranial nerves of the cavernous sinus to radiosurgery. Int J Radiat Oncol Biol Phys 27: 215-221, 1993

26. Tsang RW, Brierley JD, Panzarella T, Gospodarowicz MK, Sutcliffe SB, Simpson WJ: Radiation therapy for pituitary adenoma: treatment outcome and prognostic factors. Int J Radiat Oncol Biol Phys 30:557-565, 1994

27. van den Bergh AC, van den Berg G, Schoorl MA, Sluiter WJ, van der Vliet AM, Hoving EW, et al: Immediate postoperative radiotherapy in residual nonfunctioning pituitary adenoma: beneficial effect on local control without additional negative impact on pituitary function and life expectancy. Int J Radiat Oncol Biol Phys 67:863-869, 2007

28. Vladyka V, Liscák R, Novotný J Jr, Marek J, Jezková J: Radiation tolerance of functioning pituitary tissue in gamma knife surgery for pituitary adenomas. Neurosurgery 52:309-317, 2003

29. Woollons AC, Hunn MK, Rajapakse YR, Toomath R, Hamilton DA, Conaglen JV, et al: Non-functioning pituitary adenomas: indications for postoperative radiotherapy. Clin Endocrinol (Oxf) 53:713-717, 2000

Manuscript submitted May 15, 2012.

Accepted June 15, 2012.

Portions of this work were presented in abstract form at the 16th International Leksell Gamma Knife Society meeting, Sydney, Australia, March 25-29, 2012.

Please include this information when citing this paper: DOI: 10.3171/2012.6.GKS12986.

Address correspondence to: Wael A. Reda, M.D., Ph.D., Nasser Institute, Gamma Knife Center, 27 Hassan El-Sherif Street, Nasr City, Cairo, 11471 Egypt. email: waelareda@hotmail.com. 